\title{
Tardive Dystonia Related with Aripiprazole
}

\author{
Sunghwan Kim, Seung-Yup Lee, MinSeob Kim, and Kyoung-Uk Lee ${ }^{凶}$ \\ Department of Psychiatry, Uijeongbu St. Mary's Hospital, College of Medicine, The Catholic University of Korea, Uijeongbu, Republic of Korea
}

Tardive dystonia is characterized by sustained, generally slow involuntary twisting movements. It is estimated to occur at a frequency of $1 \%$ to $4 \%$ among patients who are taking an antipsychotic agent. Unlike the first generation antipsychotics, the second generation antipsychotics are less likely to cause neuroleptic-induced movement disorder. For aripiprazole, only a few cases have been reported for tardive dystonia. We present a young male, who developed a severe tardive dystonia after taking aripiprazole for 5 years. The patient was admitted to for the treatment of both hisdystonic and psychotic symptoms. Olanzapine was administered instead of aripiprazole and while his psychotic symptoms improved, the dystonic symptoms were continued. Therefore, olanzapine was switched to clozapine while augmenting with benzodiazepine, anti-cholinergic, and ginko biloba to control his tardive dystonia. After 2 weeks of treatment, the dystonic movement decreased remarkably.

Psychiatry Investig 2017;14(3):380-382

Key Words Aripiprazole, Clozapine, Tardive dystonia, Schizoaffective disorder, Ginkgo biloba.

\section{INTRODUCTION}

With the introduction of the second generation antipsychotics, the incidence of neuroleptic-induced movement disorders has been decreased dramatically. ${ }^{1}$ Tardive dystonia (TD), a late side effect of the antipsychotics, was also reduced. Although TD has been far less reported than tardive dyskinesia, it is frequently more disabling than dyskinesia. ${ }^{1-3}$ Whereas complete remission of tardive dyskinesia had been reported in a case series, ${ }^{4}$ no complete remission occurred in a series of 29 TD patients. ${ }^{5}$

TD is a persistent syndrome of sustained muscle contraction that produces twisting and repetitive movements or abnormal postures. ${ }^{6}$ It usually involves the head and neck, producing torticollis, retrocollis, or anterocollis, but sometimes TD involves back muscles, resulting opisthotonus and gait disturbances. ${ }^{2}$

Aripiprazole is known to have a low risk of extrapyramidal symptoms, because of its partial agonistic activity at dopa-

Received: April 12, 2016 Revised: June 14, 2016

Accepted: July 24, 2016 Available online: February 4, 2017

$\triangle$ Correspondence: Kyoung-Uk Lee, MD, PhD

Department of Psychiatry, Uijeongbu St. Mary's Hospital, College of Medicine, The Catholic University of Korea, 271 Cheonbo-ro, Uijeongbu 11765, Republic of Korea

Tel: +82-31-820-3609, Fax: +82-31-847-3630

E-mail: mindcure@catholic.ac.kr

(a) This is an Open Access article distributed under the terms of the Creative Commons Attribution Non-Commercial License (http://creativecommons.org/licenses/bync/4.0) which permits unrestricted non-commercial use, distribution, and reproduction in any medium, provided the original work is properly cited. mine receptor $\mathrm{D}_{2}$ and serotonin receptor $5 \mathrm{HT}_{1 \mathrm{~A}} \cdot{ }^{7}$ However, aripiprazole was reported to be associated with tardive dyskinesia. ${ }^{8-10}$ Furthermore, several cases of TD have also been reported with the use of aripiprazole. ${ }^{11-14}$ Herein, we report a rare case of TD related with aripiprazole in a patient with schizo affective disorder.

\section{CASE}

A 28-year-old male admitted to the department of psychiatry, Uijeongbu St. Mary's Hospital, Catholic University of Korea for torticollis and exacerbated psychotic symptoms of persecutory delusion and auditory hallucination. He was taking aripiprazole from 5 years ago due to his schizoaffective disorder, and the dose was increased from $10 \mathrm{mg} /$ day to $20 \mathrm{mg} /$ day 3 years ago. Half year later, his psychotic symptoms improved, but he began to complain about dystonia of his neck towards right side and also dystonic symptom on the left arm including abduction. His torticollis improved slightly by increasing benzodiazepine (lorazepam to $3 \mathrm{mg} /$ day) and anticholinergic (benztropine to $3 \mathrm{mg} /$ day) while reducing the aripiprazole dose, but the movement disorder was not fully diminished and worsening of the psychotic symptoms occurred.

After admission, aripiprazole was switched to olanzapine and the dosage was titrated up to $20 \mathrm{mg}$ /day on the 7th hospital day. Lorazepam and benztropine were both increased to $4 \mathrm{mg} /$ day. To further mitigate the dystonic symptoms, aman- 
tadine $200 \mathrm{mg}$ was also added. Whereas the psychotic symptoms improved, his torticollis and involuntary abduction of the left arm showed only limited response. Upon thorough physical and neurological examinations, he did not demonstrate any other dyskinetic or dystonic movements. The magnetic resonance imaging of the brain revealed no abnormality that could be associated with his dystonic symptoms. In addition, there was no familial history of movement disorders.

After 2 weeks of applying olanzapine, it was switched to clozapine in order to improve the dystonia. Clozapine was slowly built up to $300 \mathrm{mg} /$ day with the $1 \mathrm{mg}$ /day of lorazepam and $3 \mathrm{mg} /$ day of benztropine. While the dystonic symptom improved mildly without worsening of psychotic symptoms, aspiration pneumonia and confused mental status suddenly occurred at his 28th hospital day. The patient had to be transferred to the pulmonology department and treated with intravenous antibiotics for 2 weeks. During that period, all of the psychotropics including the clozapine were stopped and the dystonic symptoms were greatly aggravated. After the improvement of the aspiration pneumonia and the delirium, he was re-transferred to psychiatric department. Clozapine was carefully reapplied and benztropine was readministered. Diazepam and ginko biloba, an anti-oxidant, were given to additionally relieve TD. After 2 weeks of treatment regimen composed of clozapine $200 \mathrm{mg}$ /day, valproic acid $1000 \mathrm{mg} /$ day, benztropine $1 \mathrm{mg} /$ day, diazepam $30 \mathrm{mg} /$ day, and ginko biloba $240 \mathrm{mg} /$ day, the dystonic movement decreased remarkably and the patient was discharged at his 56th hospital day.

\section{DISCUSSION}

The patients exhibited torticollis after taking aripiprazole for 5 years, and it was improved after administering clozapine, diazepam, benztropine and ginko biloba. Aripiprazole has been associated with low risks for weight gain, metabolic disturbances and hyperprolactinemia, but it has been related with dose-dependent extrapyramidal symptoms. ${ }^{15}$ Moreover, in several studies for aripiprazole use in mood disorder, the risk for akathisia was significantly higher than placebo. ${ }^{16}$

TD has been understood in the similar pathophysiology of tardive dyskinesia, antipsychotics having a causative role with dopamine hypersensitivity. ${ }^{1718}$ Still, they differin several areas: different phenomenological manifestations (torticollis -displayed in our case), different risk factor (young and male predominance -also correlatingto our case), and different reactions to anti-cholinergics which can improve tardive dystonia but may exacerbate tardive dyskinesia. ${ }^{19}$

TD can be related with severe life-threatening complications such as aspiration pneumonia due to laryngeal dystonia. ${ }^{14}$ In this case, there is also a possibility that the aspiration pneumonia was induced by TD since the dystonic symptoms involved his neck and as he had no other specific risk factors for aspiration. Therefore an extra caution should be taken when a patient with dystonic symptoms shows signs of aspiration such as cough, fever shortness of breath, dysphagia and etc.

Aripiprazole has been known as dopamine partial agonist, but it has high affinity for $\mathrm{D}_{2}$ receptors with weak affinity for $\mathrm{D}_{1}$ receptors, and this receptor profile can lead to an imbalance between $\mathrm{D}_{1}$ - and $\mathrm{D}_{2}$-mediated striatal outputs. ${ }^{12,17}$ As a result, chronic use of aripiprazole may potentially cause TD as well as tardive dyskinesia. On the contrary, there were alsocase reports of tardive symptoms being improved by aripiprazole for both $\mathrm{TD}^{20,21}$ and tardive dyskinesia. ${ }^{22,23}$ Therefore, not only the antipsychotic agent but also the individual factors may play a role in the pathogenesis of TD.

While chronic neuroleptic usage results in high $\mathrm{D}_{2}$ receptor blockade, lower occupancy for $\mathrm{D}_{1}$ receptors may lead to sensitization of the $\mathrm{D}_{1}$-mediated striatal output, which in turn leads to abnormal movement. ${ }^{17}$ In a prior meta-analysis, clozapine showed lower $\mathrm{D}_{2}$ receptor occupancy $(61.7 \%)$ than other atypical antipsychotics (82.9-96.5\%) except for quetiapine (49.1\%). ${ }^{24}$ Compared to typical antipsychotics, clozapine has relatively higher $\mathrm{D}_{1}$ receptor occupancy and this may contribute to the restoration of the $\mathrm{D}_{1}$ and $\mathrm{D}_{2}$ imbalance. ${ }^{14,17}$ Worsening of TD had been observed in our case with the discontinuation of clozapine, suggesting breach of partially restored $\mathrm{D}_{1}-\mathrm{D}_{2}$ balance. Clozapine was stopped temporally in the treatment course due to the concerns of clozapine-induced sialorrhea exacerbating the aspiration pneumonia. The authors speculate that the improvement of TD that occurred following the re-introduction of clozapine owes to the restored $D_{1}$ and $D_{2}$ imbalance by blockage of over-sensitized $D_{1}$-mediated striatal output. As in our case, there was also a report of aripiprazole-induced TD resolved by clozapine previously. ${ }^{25}$

Once developed, TD usually persists. The conventional approaches to control TD symptoms include administration of benzodiazepine, anticholinergic, dopaminergic or dopaminedepletingagents (amantadine or tetrabenazine). According to a recent evidence-based guideline for tardive syndromes, clonazepam and ginkgo biloba were suggested for tardive syndromes (both level B). ${ }^{26}$ In the same review, the level of evidence for amantadine was lower (level C). Yet, there was another double blinded randomized control trial that demonstrated a positive result, ${ }^{27}$ but not included in the review. ${ }^{28}$ Although the evidence was limited for TD, we additionally prescribed amantadine as our case was regarded potentially life threatening due to aspiration pneumonia in association with TD. If refractory, botulinum toxin injection, electroconvulsive therapy, and pallidal deep brain stimulation can also be considered as a treatment modality. In this case, patient's 
dystonic symptoms were successfully controlled with clozapine $200 \mathrm{mg}$, diazepam $30 \mathrm{mg}$ and ginkgo biloba $240 \mathrm{mg}$ for 2 weeks.

In conclusion, although it is not frequent, aripiprazole may cause tardive dystonia. Therefore, a careful monitoring is advised when prescribing aripiprazole in order to detect TD early and to prevent accompanying complications.

\section{REFERENCES}

1. Tarsy D, Lungu C, Baldessarini RJ. Epidemiology of tardive dyskinesia before and during the era of modern antipsychotic drugs. Handb Clin Neurol 2011;100:601-616.

2. Adityanjee, Aderibigbe YA, Jampala VC, Mathews T. The current status of tardive dystonia. Biol Psychiatry 1999;45:715-730.

3. Ryu S, Yoo JH, Kim JH, Choi JS, Baek JH, Ha K, et al. Tardive dyskinesia and tardive dystonia with second-generation antipsychotics in nonelderly schizophrenic patients unexposed to first-generation antipsychotics: a cross-sectional and retrospective study. J Clin Psychopharmacol 2015;35:13-21.

4. Khouzam HR. Identification and management of tardive dyskinesia: a case series and literature review. Postgrad Med 2015;127:726-737.

5. Wojcik JD, Falk WE, Fink JS, Cole JO, Gelenberg AJ. A review of 32 cases of tardive dystonia. Am J Psychiatry 1991;148:1055-1059.

6. Burke RE, Fahn S, Jankovic J, Marsden CD, Lang AE, Gollomp S, et al. Tardive dystonia: late-onset and persistent dystonia caused by antipsychotic drugs. Neurology 1982;32:1335-1346.

7. Shapiro DA, Renock S, Arrington E, Chiodo LA, Liu LX, Sibley DR, et al. Aripiprazole, a novel atypical antipsychotic drug with a unique and robust pharmacology. Neuropsychopharmacology 2003;28:1400-1411.

8. Maytal G, Ostacher M, Stern TA. Aripiprazole-related tardive dyskinesia. CNS Spectr 2006;11:435-439.

9. Schwartz T, Raza S. Aripiprazole (abilify) and tardive dyskinesia. P T 2008;33:32-34.

10. Goyal R, Devi SH. A case of aripiprazole induced tardive dyskinesia in a neuroleptic-naive patient with two years of follow up. Clin Psychopharmacol Neurosci 2014;12:69-71.

11. Pinninti NR, Mago R, Adityanjee. Tardive dystonia-associated prescription of aripiprazole. J Neuropsychiatry Clin Neurosci 2006;18: 426-427.

12. Lim HK, Pae CU, Lee C, Lee CU. Tardive dystonic symptoms associated with aripiprazole treatment. Prog Neuropsychopharmacol Biol Psychiatry 2008;32:589-590.

13. Friedman JH. Tardive dystonia due to aripiprazole use in a neuroleptic-naive patient. J Clin Psychiatry 2010;71:652-653.
14. Matsuda N, Hashimoto N, Kusumi I, Ito K, Koyama T. Tardive laryngeal dystonia associated with aripiprazole monotherapy. J Clin Psychopharmacol 2012;32:297-298.

15. Cha DS, McIntyre RS. Treatment-emergent adverse events associated with atypical antipsychotics. Expert Opin Pharmacother 2012;13:15871598.

16. Gao K, Kemp DE, Fein E, Wang Z, Fang Y, Ganocy SJ, et al. Number needed to treat to harm for discontinuation due to adverse events in the treatment of bipolar depression, major depressive disorder, and generalized anxiety disorder with atypical antipsychotics. J Clin Psychiatry 2011;72:1063-1071.

17. Trugman JM, Leadbetter R, Zalis ME, Burgdorf RO, Wooten GF. Treatment of severe axial tardive dystonia with clozapine: case report and hypothesis. Mov Disord 1994;9:441-446.

18. Sachdev PS. Neuroleptic-induced movement disorders: an overview. Psychiatr Clin North Am 2005;28:255-274, x.

19. van Harten PN, Kahn RS. Tardive dystonia. Schizophr Bull 1999;25: 741-748.

20. Kato K, Andoh H, Matsumoto H. Case of tardive dystonia improved by aripiprazole. Psychiatry Clin Neurosci 2010;64:337-338.

21. Takagai S, Nakasato K, Suzuki K, Kasai E, Isogai S, Morimoto S, et al. Improvement in intractable tardive dystonia in bipolar disorder after aripiprazole treatment: a case report. J Clin Psychopharmacol 2012;32:563-564.

22. Grant MJ, Baldessarini RJ. Possible improvement of neuroleptic-associated tardive dyskinesia during treatment with aripiprazole. Ann Pharmacother 2005;39:1953.

23. Kantrowitz JT, Srihari VH, Tek C. Resolution of tardive dyskinesia after addition of aripiprazole to haloperidol depot. J Clin Psychopharmacol 2007;27:525-526.

24. Lako IM, van den Heuvel ER, Knegtering H, Bruggeman R, Taxis K. Estimating dopamine D2 receptor occupancy for doses of 8 antipsychotics: a meta-analysis. J Clin Psychopharmacol 2013;33:675-681.

25. Joe S, Park J, Lim J, Park C, Ahn J. Remission of irreversible aripiprazole-induced tardive dystonia with clozapine: a case report. BMC Psychiatry 2015;15:253.

26. Bhidayasiri R, Fahn S, Weiner WJ, Gronseth GS, Sullivan KL, Zesiewicz TA, et al. Evidence-based guideline: treatment of tardive syndromes: report of the Guideline Development Subcommittee of the American Academy of Neurology. Neurology 2013;81:463-469.

27. Pappa S, Tsouli S, Apostolou G, Mavreas V, Konitsiotis S. Effects of amantadine on tardive dyskinesia: a randomized, double-blind, placebo-controlled study. Clin Neuropharmacol 2010;33:271-275.

28. Angus S, Sugars J, Boltezar R, Koskewich S, Schneider NM. A controlled trial of amantadine hydrochloride and neuroleptics in the treatment of tardive dyskinesia. J Clin Psychopharmacol 1997;17:88-91. 